\title{
The Implications of Oral History for Librarians
}

\begin{abstract}
The author lists five major implications for research librarians which are arising out of the rapid growth of oral history archives. (1) They create rather than simply acquire primary research material. (2) They offer new possibilities of service and new responsibilities. (3) They present problems of integration into conventional library collections. (4) Librarians must furnish access bibliographically to these newer materials. (5) Problems of bibliographical control should be studied as soon as possible.
\end{abstract}

O RAL HISTORY is no longer an experiment; it is a healthy movement. A group of historians, librarians, doctors, psychologists, and lawyers recently met at the Second Oral History Colloquium ${ }^{1}$ to discuss techniques and philosophies and to found the Oral History Association. ${ }^{2}$ The papers and discussions at this meeting showed that, as a movement, oral history has significant implications for research librarians, especially those in academic libraries.

Oral history is a record of recall. The record is authored by an individual who participated in, or observed at close range, events whose documentation will aid future researchers in understanding some facet of twentieth-century life. The oral author is aided in his recall by an interviewer versed both in the segment of life to be recorded and in appropriate

\footnotetext{
1 The Second Oral History Colloquium was held at Arden House, November 18-21, 1967, under the sponsorship of Columbia University.

2 Information may be obtained from James V. Mink, director, Oral History Project, Powell library, University of California at Los Angeles.
}

Mrs. Zachert is Assistant Professor, Library School, Florida State University. techniques for creating this unique record. To this extent oral history is a collaboration: the oral author is the contributor of substance, the interviewer is the contributor of recording skill. Practitioners of the art are currently engaged in formulating techniques to safeguard both the accuracy of the record and convenience in its use. For accuracy the record is tape recorded; for convenience it is usually transcribed. Groups of oral history interviewers are usually organized into an oral history "office," "center," "program," or "archives," although loners are not unknown. Groups or single interviewers may be an adjunct of a research library or may more usually be autonomous within an academic context. In either event, tapes, transcriptions, or both almost always come to rest in a library while awaiting their ultimate users.

The alert research librarian will perceive at once that there are many implications in this oral history movement for libraries and for librarians. To an observer at the colloquium's sessions five implications seem of immediate significance.

1. Oral history, for a library, is a way of creating primary source materials in 
contrast to its time-honored responsibility of acquiring them. For the librarian, then, building an oral archive becomes a unique opportunity for a creative intellectual contribution. Research librarians are typically specialists, either through academic accomplishment or through informal but penetrating study of the materials in their collections. Typically also, research librarians have a near-intuitive rapport with other individuals that comes from long and intensive public service. To become builders of oral archives librarians must add analytic skill to identify what is significant in our own times in order to define the appropriate scope for each oral history project they undertake. Librarians must also learn interviewing and recording techniques. If research librarians do not rise to this occasion, a rare creative opportunity will escape them.

2. Oral archives offer new service possibilities for research libraries; they also present new responsibilities. The oral author's product is legally his to deposit or to assign to the institution which houses and services it. In either casedeposit or assignment-the oral author can stipulate conditions under which his material may be used by researchers. Under these circumstances the library must fulfill the author's conditions or be liable for its failure to do so. If the library chooses to copyright the oral history tapes or transcripts, it has the added responsibility to make sure the copyrighted material is used but not infringed. Libraries now receiving oral archives, whether or not they themselves created the materials, have already had these new responsibilities thrust upon them. Libraries contemplating embarkation on a project of their own or cooperation in a project with an academic department should inform themselves in respect to these new responsibilities and vulnerabilities.

3. A further responsibility for the li- brary housing oral archives is that of integrating tapes and transcripts into the collections of primary research materials, while at the same time observing conditions of housing uniquely required by the unusual formats. Most oral history projects generate series of records rather than single items. The name "oral archives" suggests that these materials may be better handled through the archivist's concepts of provenance and record series than as individual items.

4. The responsibility for bibliographic control follows, and again a solution may derive from the archivist's concepts. Oral archives can be, perhaps should be, described as are collections of personal or official papers. But providing intellectual access to primary source materials is only half the battle. Physical access must also be provided for researchers. It is not too soon in the oral history movement to recommend the inclusion of oral archives in the National Union Catalog of Manuscript Collections. Lending themselves to the same kind of description as that used for papers, oral archives can be included without requiring any modification in the format of NUCMC. Their use along with the kinds of materials already described in NUCMC stipulates their inclusion for the convenience of the researcher. Why should he have to search different tools for such closely related primary materials? The fact that inclusion of oral archives is already under discussion between oral historans and NUCMC suggests that all research librarians need to keep an eye on the situation. Even those librarians whose own institutions do not include oral archives will want to be able to direct their patrons to collections that can aid research under way.

5. Finally, oral history archives offer librarians opportunity for research into the problems of retrieving information from additional storage media-tapes and transcriptions. All appropriate tech- 
niques, including machine techniques, should be investigated while the total body of oral archives is relatively small. The urgency to index in depth may not be apparent with the present volume of material. But one lesson that seems clear is that the body of material is growing rapidly with no endpoint in sight. Lessons expensively learned from journal and technical report literature seem appropriate for modification in the new context.

Lest research librarians feel helpless in the face of these implications, the following readings are suggested for an orientation. $^{3}$
"Goals and Guidelines for Oral History." Oral History Association, c/o James V. Mink, Director, Oral History Program, Powell Library, University of California at Los Angeles. 1967. Mimeographed.

Gottschalk, Louis R., et al. Use of Personal Documents in History, Sociology and Anthropology. Social Science Research Council, 1945. (Paperback)

Bingham, Walter and Bruce Moore. How to Interview. 4th ed. Harper, 1959.

${ }^{3}$ For additional items relating specifically to oral history, see Donald J. Schippers and Adelaide G. Tusler, A Bibliography of Oral History (Oral History Associations, Miscellaneous Publications, No. 1 [Los Angeles: The Association, 1967]. Available from James V. Mink, Director, Oral History Program, Powell library, University of California at Los Angeles. 50 cents.).

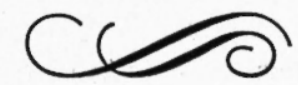

